\title{
The epidemiological profile of pediatric patients admitted to the general intensive care unit in an Ethiopian university hospital
}

This article was published in the following Dove Press journal:

International Journal of General Medicine

29 January 2015

Number of times this article has been viewed

\section{Teshome Abebe \\ Mullu Girmay \\ Girma G/Michael \\ Million Tesfaye}

Department of Anesthesia, Jimma

University, Jimma, Ethiopia
Correspondence: Million Tesfaye Department of Anesthesia, Jimma University, PO Box 378, Jimma, Ethiopia Tel +25I 9 I 3542906

Email mtesfayel@gmail.com
Background: In least developing countries, there are few data on children's critical care. This makes the provision of aid and improvement of outcome difficult.

Objectives: To describe admission and outcome patterns of children managed in a general intensive care unit at Jimma University Specialized Hospital (JUSH), Ethiopia, over a 5-year period.

Methods: A retrospective cross-sectional study design was used. All children from birth to 14 years of age who were admitted to the general ICU of the hospital from 2009-2013 were included. Patient charts and ICU documentation log were reviewed.

Results: A total of 170 children were admitted to the ICU of JUSH over the study period. The greater share was taken by males $(54.7 \%)$, with a male-to-female ratio of $1.2: 1$. The overall mortality rate was $40 \%$. The majority of the children were in the age range of 10-14 years (38.8\%). Of the total number of patients admitted, $34.7 \%$ were trauma cases, $45.8 \%$ of whom died. The highest percentage, $69.5 \%$, of trauma patients were admitted for head injuries. Among the trauma cases, burn and polytrauma were the second and third leading causes $(15.3 \%)$ of admission. Postoperative patients and medical patients accounted for the rest of the admitted cases (28.2\% and $27.6 \%$ of the cases respectively).

Conclusion: The leading cause of admission and death was trauma. Postoperative and medical causes of admission were also significant. The mortality rate in the ICU was very high, and this could be due to various factors. Further research benchmarking and interventions are highly recommended.

Keywords: trauma, critical care, pediatric, ICU, ventilation, oxygenation

\section{Introduction}

According to the World Health Organization, the major causes of death in under-fiveyear-old children in developing countries ${ }^{1}$ are preventable and curable. Improving outcome is possible by well-equipped and well-staffed intensive care units, since dramatic decreases in mortality and morbidity have been documented by such measures. ${ }^{2,3}$ Intensive care could reduce mortality rates by $15 \%$ to $60 \%,{ }^{2}$ and many studies have demonstrated its unquestionable benefit. ${ }^{4,5}$

Well-equipped intensive care units staffed with intensivists have shown better outcomes. $^{6,7}$ There is no organized database in Africa concerning children admitted to critical care. In developed countries, death before discharge is a rare outcome. ${ }^{8}$ In least developing countries there are few data on children's critical care, and this makes the provision of aid and improvement of outcome difficult. ${ }^{9}$ Moreover, in Africa, deficiencies in children's critical care are related to drugs, oxygen, blood products, and monitoring equipment. ${ }^{10}$ As a result, the quality of critical care provided in low-income 
countries is of a very low order, ${ }^{9}$ and mortality as high as $40 \%$ has been reported. ${ }^{11}$

Previous investigations at Jimma University Specialized Hospital (JUSH) have generally addressed admissions and outcomes covering all ages in the general intensive care unit (GICU), but none have paid particular attention to the pediatric age group. Two previous studies in this intensive care unit had reported that the overall intensive care unit mortality rate was high $\left(50.4 \%{ }^{12}\right.$ and $\left.37.7 \%{ }^{13}\right)$.

Thus, the aim of this study is to provide epidemiological data on admission and outcome patterns of children managed at a GICU.

\section{Methods}

\section{Study setting and period}

This study was conducted in the ICU of JUSH. The hospital is located in Jimma town, Oromia Region, $350 \mathrm{~km}$ southwest of Addis Ababa. It is the only specialized teaching and referral hospital in the southwestern part of Ethiopia, with 450 beds and 558 health professionals, where a multidisciplinary team of diverse professionals provide a range of health care services for approximately 9,000 inpatients and 80,000 outpatients each year. Annually, 1,700 children are admitted to the pediatrics department. Major causes of pediatric admission to the hospital are pneumonia, malaria, infections of newborn, and tuberculosis. Annual deliveries in the hospital are about 2,500. There are about 30 critical care admissions per year. The GICU was established in 2005. Currently, it has six beds with mechanical ventilators for patients admitted from different departments of the hospital.

\section{Study design and participants}

A retrospective cross-sectional study design was used. All pediatric patients from birth to 14 years of age who were admitted to the GICU of the hospital from September 2009 to September 2013 were included. Patient charts and ICU documentation log were reviewed. Important variables on demographic characteristics, causes of admission, breathing, nutrition, and management outcomes were retrieved from the chart and logbook. Computation of the $P$-value was done by the chi-square test. $P<0.005$ was considered to be statistically significant.

\section{Result}

\section{Demographic characteristics with respective outcomes}

A total of 170 pediatrics patients were admitted to the ICU of JUSH over the study period. A greater share was taken by the male children $(54.7 \%)$, with a male-to-female ratio of 1.2:1. The overall mortality rate was $40 \%$. The majority of the pediatric patients $(38.8 \%)$ were found in the age range of 10-14 years. Only ten patients (5.9\%) were admitted in the age group of 1-6 months (Table 1).

\section{Indications, length of stay, and outcome after admission}

Of the total number of patients admitted, $34.7 \%$ were trauma cases, $45.8 \%$ of whom died after admission. The highest number of trauma patients were admitted (69.5\%) due to head injuries. Burns and polytraumas were the second and third leading causes of admission in $15.3 \%$ of the cases.

Among the study subjects, traumas and postoperative admission are common in children aged 6 to 14 years, with associated mortality rates of $45.8 \%$ and $50 \%$ respectively.

Table I Patient characteristics

\begin{tabular}{|c|c|c|c|}
\hline Variables & $\begin{array}{l}\text { Admission } \\
\mathbf{N}(\%) \\
\end{array}$ & $\begin{array}{l}\text { Improved } \\
\mathbf{N}(\%)\end{array}$ & $\begin{array}{l}\text { Dead } \\
\mathbf{N}(\%)\end{array}$ \\
\hline \multicolumn{4}{|l|}{$\operatorname{Sex}(n=170)$} \\
\hline Male & $93(54.7)$ & $60(64.5)$ & $33(35.5)$ \\
\hline Female & $77(45.3)$ & $42(24.7)$ & $35(45.5)$ \\
\hline \multicolumn{4}{|l|}{ Age $(n=170)$} \\
\hline I-6 months & $10(5.9)$ & $8(80)$ & $2(20)$ \\
\hline 7 months-I year & $14(8.2)$ & $9(64.3)$ & $5(35.7)$ \\
\hline $2-5$ years & $37(21.8)$ & $22(59.5)$ & $15(40.5)$ \\
\hline $6-9$ years & $43(25.3)$ & $23(53.5)$ & $20(46.5)$ \\
\hline 10-14 years & $66(38.8)$ & $30(45.5)$ & $36(54.5)$ \\
\hline Trauma & $59(34.7)$ & $32(54.2)$ & $27(45.8)$ \\
\hline Postoperative & $48(28.2)$ & $24(50)$ & $24(50)$ \\
\hline Medical & $47(27.6)$ & $24(5 \mid . I)$ & $23(48.9)$ \\
\hline Airway obstruction & $16(9.4)$ & $14(87.5)$ & $2(12.5)$ \\
\hline \multicolumn{4}{|l|}{ Length of stay } \\
\hline$<$ I day & $21(12.3)$ & $0(0)$ & $21(100)$ \\
\hline I-2 days & $40(23.5)$ & $16(40)$ & $24(60)$ \\
\hline $2-7$ days & $56(32.9)$ & $38(67.5)$ & $18(32.1)$ \\
\hline $7-14$ days & $30(17.6)$ & $23(76.7)$ & $7(23.3)$ \\
\hline 14-28 days & $12(7)$ & II (9I.7) & I $(8.3)$ \\
\hline Above 28 days & II (6.4) & $3(27.3)$ & $8(72.7)$ \\
\hline \multicolumn{4}{|l|}{ Trauma $(n=59)$} \\
\hline Head injury & $4 \mid(69.5)$ & $30(73.2)$ & II (26.8) \\
\hline Burn & $9(15.3)$ & $3(33.3)$ & $6(66.7)$ \\
\hline Polytrauma & $9(I 5.3)$ & 7 (77.8) & $2(22.2)$ \\
\hline \multicolumn{4}{|l|}{ Medical $(n=47)$} \\
\hline Shock & $8(17)$ & $4(50)$ & $4(50)$ \\
\hline Guillain-Barre syndrome & $7(14.8)$ & $2(28.6)$ & $5(71.4)$ \\
\hline Tetanus & $6(12.7)$ & $4(66.7)$ & $2(33.3)$ \\
\hline Congestive heart failure & $6(12.7)$ & $2(33.3)$ & $4(66.7)$ \\
\hline Pneumonia & $5(10.6)$ & $4(80)$ & $I(20)$ \\
\hline Renal failure & $4(8.5)$ & I (25) & $3(75)$ \\
\hline Tuberculosis & $2(4.3)$ & $0(0)$ & $2(100)$ \\
\hline Asthma & $2(4.3)$ & I (50) & I (50) \\
\hline Myocardial Infarction & $2(4.3)$ & I (50) & I (50) \\
\hline Others $^{\mathrm{a}}$ & $5(10.6)$ & $5(100)$ & $0(0)$ \\
\hline
\end{tabular}

Note: aAnemia, poisonings, meningitis, sepsis, malaria. 
Medical cases are also notable, particularly in the younger age group (1-5 years). Age and mortality showed no correlation at $95 \%$ confidence interval ( $P$-value is 0.222066 ).

Postoperative patients and medical patients made up the rest of the admissions $(28.2 \%$ and $27.6 \%$ of the cases respectively). Shock is the leading cause of medical admission (17\%), followed by Guillain-Barré Syndrome (14.8\%), pneumonia (10.6\%), tuberculosis (4.3\%), asthma (4.3\%), and renal failure (8.5\%) (Table 1).

Children's length of stay in critical care has shown a significant association with outcome $(P$-value $=0.0000)$. The highest number of deaths is documented in those patients who stayed for less than a day and more than 28 days. Those who stayed in the ICU between 7 and 14 days had relatively low mortality (about 8.3\%) (Table 1).

\section{Ventilation and oxygenation}

Of the 170 pediatric patients admitted to the ICU, 63 (37.1\%) were mechanically ventilated from initial admission to discharge or death; the percentage of patients spontaneously breathing with face mask was $22.4 \% ; 15.3 \%$ were spontaneously breathing without any assistance; and spontaneous breathing with nasal cannula was used to assist children oxygenation in $15.9 \%$. Sixteen patients $(9.4 \%)$ had tracheostomy done (Figure 1).

\section{Discussion}

Good quality health care has a profound effect on reduction of childhood mortality in developing countries. ${ }^{14,15}$ However, in these countries, this is one of the fragile components of the health care system, as are emergency and critical care. ${ }^{16,17}$ The challenge is also related to rapid identification, prioritization, and urgent treatment. ${ }^{17-19}$

The problem is also related to the fact that in African countries the ICUs are mixed (ie, surgical, pediatric, obstetrics), having no functional emergency medical response system, inadequate transportation of trauma victims, and inadequate resources. ${ }^{11}$

It is controversial to compare specialist and nonspecialist ICUs in terms of outcome. ${ }^{20}$ Characterizing the population, clinical settings, and environments and cases in which deaths occur can help ICUs with resource planning, setting organizational procedures, and training personnel. ${ }^{21}$

We have analyzed 170 pediatric patients admitted to the intensive care unit over a 5-year period. Our finding of male predominance is in line with that of other studies. ${ }^{22-24}$ It has been documented elsewhere that $50 \%$ of deaths of children in hospital occur within 24 hours of admission. ${ }^{25,26}$ However the higher mortality within 24 hours $(100 \%)$, in our study might be due to the evident higher numbers of admissions and fatality from trauma cases.

Length of stay has shown a significant statistical association with children outcome, with a $P$-value of 0.0000 on the chi-square test. Unfavorable outcome (72.7\% mortality) was associated with a long stay ( $>28$ days). In a study based in Australia, more than two-thirds of children with long hospital stay had the same unfavorable outcome. ${ }^{27}$ A number of medical, social, psychological, and institutional factors aggravate the long length of stay in the intensive care unit. ${ }^{28}$

Mortality was higher in a specific age group, though no statistical association was established between children's age and outcome $(P$-value $=0.222066)$. This might be due to the fact that the incidence of mortality is higher in trauma patients and these traumas are common in children aged 6-10 years.

The overall mortality found by this study was $40 \%$, which has also been reported in previous studies conducted in the same setting, but addressing adults. ${ }^{12,13}$ The outcome is also the same when it comes to the pediatrics population. This might be due to inadequate staffing, experience, and resources as in any other sub-Saharan African countries. ${ }^{12,25,29}$

In our study, the leading cause of both admission and death was trauma. Of the total number of patients admitted

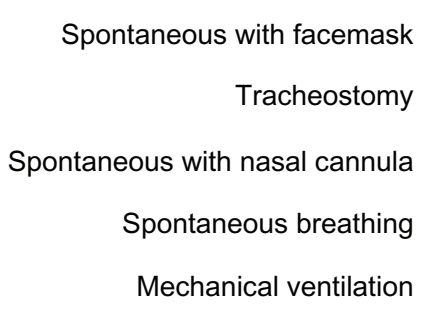

Mechanical ventilation

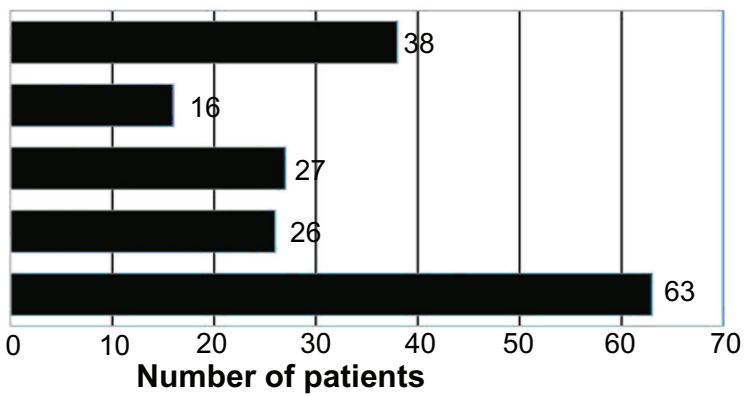

Figure I Total number of children admitted $(n=\mid 70)$ and breathing characteristics: spontaneous with face mask $(22.4 \%)$, tracheostomy $(9.4 \%)$, spontaneous with nasal cannula (I5.9\%), only spontaneous breathing (15.3), and mechanical ventilation (37.1\%). 
to the ICU over the study period as a result of trauma, $69.5 \%$ had head injuries, and $26.8 \%$ of these died. The percentage of patients who died of trauma in this study was $45.8 \%$. This figure is very consistent with and comparable to that reported by other studies, as trauma in children is the leading cause of both mortality and morbidity in over $50 \%$ of all childhood deaths. ${ }^{30,31}$

A major deficiency of critical care delivery in developing countries is with respect to resources, specifically oxygen. ${ }^{17}$ Implementation of the oxygen concentrator system has proved to be instrumental in decreasing the mortality rate of pediatric patients in critical care, ${ }^{32}$ with a $35 \%$ decrease in fatalities reported among children with pneumonia. ${ }^{15} \mathrm{Of}$ the total number of patients admitted, the proportion of patients mechanically ventilated was $37 \%$, which is comparable to the findings of other studies. ${ }^{33,34}$ The rest of the patients, $22.4 \%$ and $15.9 \%$, were spontaneously breathing with face mask and nasal cannula.

Medical patients form $27.6 \%$ of the total number of patients admitted. Shock (17\%), Guillain-Barré syndrome (14.8\%), tetanus $(12.7 \%)$, congestive heart failure $(12.7 \%)$, and pneumonia were the other major causes of admission.

In developing countries, tetanus is a common problem, unlike the situation in the developed world. ${ }^{12,35}$ In a study conducted at JUSH, the case fatality of tetanus was $38 \%$. Further, most of the patients died within the first few days as a result of respiratory failure. ${ }^{35}$ In our study, the total number of patients admitted as a result of tetanus was $12.7 \%, 33.3 \%$ of whom died, and this finding is consistent with that of previous studies. A previous study on critical care outcomes in the same setting has also revealed higher fatalities $(53.3 \%)^{12}$ among tetanus patients, which is higher than that reported here. This is because only children were included in our study.

Intensive care units should be appropriately staffed and equipped for better outcomes. Meticulous attention should be given to resources to improve outcome. To attract funds and the attention of key stakeholders, data should be made available describing the status of critical care in developing countries.

In conclusion, the leading cause of admission and death was trauma. Postoperative and medical causes of admission were also significant. The mortality rate in the ICU is very high and warrant further research, benchmarking, and intervention.

\section{Ethics and data collection}

Prior to data collection, an official letter from the Student Research Program (SRP) and the School of Anesthesia was submitted to the clinical director and the hospital administration. It was assured that the patients' matters would be kept confidential. After a checklist was prepared, all pediatric patients' charts and ICU records over the 5-year period of the study were reviewed from the card room to extract the relevant data. All necessary information was retrieved from these patients' charts and ICU patients' documentation log. The data were collected by the principal investigator after being suitably briefed and trained by the coauthors of this article. After data were collected, their completeness and consistency were checked. The data were edited, coded, entered into SPSS Windows Version 17, and finally cleared.

\section{Disclosure}

The authors report no conflicts of interest in this work.

\section{References}

1. Bryce J, Boschi-Pinto C, Shibuya K, Black RE. WHO estimates of the causes of death in children. Lancet. 2005;365(9465):1147-1152.

2. Young M, Birkmeyer J. Potential reduction in mortality rates using an intensivist model to manage intensive care units. Eff Clin Pract. 1999;3(6):284-289.

3. Earle M, Natera OM, Zaslavsky A, et al. Outcome of pediatric intensive care at six centers in Mexico and Ecuador. Crit Care Med. 1997;25(9):1462-1467.

4. Butt W, Shann F, Tibballs J, et al. Long-term outcome of children after intensive care. Crit Care Med. 1990;18(9):961-965.

5. Gemke R, Bonsel GJ, Van Vught A. Long-term survival and state of health after paediatric intensive care. Arch Dis Child. 1995;73(3): 196-201.

6. Epstein D, Brill JE. A history of pediatric critical care medicine. Pediatr Res. 2005;58(5):987-996.

7. Randolph AG, Gonzales CA, Cortellini L, Yeh TS. Growth of pediatric intensive care units in the United States from 1995 to 2001. J Pediatr. 2004;144(6):792-798.

8. Jones S, Rantell K, Stevens K, et al. Outcome at 6 months after admission for pediatric intensive care: a report of a national study of pediatric intensive care units in the United kingdom. Pediatrics. 2006;118(5):2101-2108.

9. Dunser MW, Baelani I, Ganbold L. A review and analysis of intensive care medicine in the least developed countries. Crit Care Med. 2006;34(4):1234-1242.

10. Okafor U. Challenges in critical care services in Sub-Saharan Africa: perspectives from Nigeria. Indian J Crit Care Med. 2009;13(1):25.

11. Kwizera A, Dunser M, Nakibuuka J. National intensive care unit bed capacity and ICU patient characteristics in a low income country. $B M C$ Res Notes. 2012;5:475.

12. Smith ZA, Ayele Y, McDonald P. Outcomes in critical care delivery at Jimma University Specialised Hospital, Ethiopia. Anaesth Intensive Care. 2013;41(3):363-368.

13. Agalu A, Woldie M, Ayele Y, Bedada W. Reasons for admission and mortalities following admissions in the intensive care unit of a specialized hospital, in Ethiopia. Int J Med Medical Sci. 2014;6(9):195-200.

14. English M. Child survival: district hospitals and paediatricians. Arch Dis Child. 2005;90(9):974-978.

15. Duke T, Wandi F, Jonathan M, et al. Improved oxygen systems for childhood pneumonia: a multihospital effectiveness study in Papua New Guinea. Lancet. 2008;372(9646):1328-1333.

16. Razzak JA, Kellermann AL. Emergency medical care in developing countries: is it worthwhile? Bull World Health Organ. 2002;80(11): 900-905. 
17. Nolan T, Angos P, Cunha AJ, et al. Quality of hospital care for seriously ill children in less-developed countries. Lancet. 2001;357(9250): 106-110.

18. Thomson N. Emergency medical services in Zimbabwe. Resuscitation. 2005;65(1):15-19.

19. Molyneux E, Ahmad S, Robertson A. Improved triage and emergency care for children reduces inpatient mortality in a resource-constrained setting. Bull World Health Organ. 2006;84(4):314-319.

20. Cogo PE, Poole D, Codazzi D, et al. Outcome of children admitted to adult intensive care units in Italy between 2003 and 2007. Intensive Care Med. 2010;36(8):1403-1409.

21. Lanetzki CS, de Oliveira CA, Bass LM, Abramovici S, Troster EJ. The epidemiological profile of Pediatric Intensive Care Center at Hospital Israelita Albert Einstein. Einstein (São Paulo). 2012;10(1):16-21.

22. El Halal MG, Barbieri E, Mombelli Filho R, de Andrade Trotta E, Carvalho PRA. Admission source and mortality in a pediatric intensive care unit. Indian J Crit Care Med. 2012;16(2):81.

23. Alievi PT, Carvalho PR, Trotta EA, Mombelli Filho R. The impact of admission to a pediatric intensive care unit assessed by means of global and cognitive performance scales. J Pediatr (Rio J). 2007;83(6): 505-511.

24. Kapil D, Bagga A. The profile and outcome of patients admitted to a pediatric intensive care unit. Indian J Pediatr. 1993;60(1):5-10.

25. Baker TIM. Pediatric emergency and critical care in low-income countries. Pediatr Anesth. 2009;19(1):23-27.

26. Molyneux E. Paediatric emergency care in developing countries. Lancet. 2001;357(9250):86-87.
27. Namachivayam P, Taylor A, Montague T, et al. Long-stay children in intensive care: long-term functional outcome and quality of life from a 20-yr institutional study. Pediatr Crit Care Med. 2012;13(5): $520-528$.

28. Gruenberg DA, Shelton W, Rose SL, Rutter AE, Socaris S, McGee G. Factors influencing length of stay in the intensive care unit. Am J Crit Care. 2006;15(5):502-509.

29. Towey R, Ojara S. Intensive care in the developing world. Anaesthesia. 2007;62(Suppl 1):32-37.

30. Mazzola CA, Adelson PD. Critical care management of head trauma in children. Crit Care Med. 2002;30(11):S393-S401.

31. Şahin S, Bekâr A, Doğan Ş, Kocaeli H, Aksoy K. Critical care management of severe head injury in children. Ulus Travma Acil Cerrahi Derg. 2005;11(4):336-343.

32. Enarson $\mathrm{P}$, La Vincente S, Gie R, Maganga E, Chokani C. Implementation of an oxygen concentrator system in district hospital paediatric wards throughout Malawi. Bull World Health Organ. 2008;86(5):344-348.

33. Farias JA, Frutos F, Esteban A, et al. What is the daily practice of mechanical ventilation in pediatric intensive care units? A multicenter study. Intensive Care Med. 2004;30(5):918-925.

34. Silva DC, Shibata AR, Farias JA, Troster EJ. How is mechanical ventilation employed in a pediatric intensive care unit in Brazil? Clinics (Sao Paulo, Brazil). 2009;64(12):1161-1166.

35. Amare A, Yami A. Case-fatality of adult tetanus at Jimma University Teaching Hospital, Southwest Ethiopia. Afr Health Sci. 2011;11(1) 36-40.
International Journal of General Medicine

\section{Publish your work in this journal}

The International Journal of General Medicine is an international, peer-reviewed open-access journal that focuses on general and internal medicine, pathogenesis, epidemiology, diagnosis, monitoring and treatment protocols. The journal is characterized by the rapid reporting of reviews, original research and clinical studies across all disease areas.

\section{Dovepress}

A key focus is the elucidation of disease processes and management protocols resulting in improved outcomes for the patient.The manuscript management system is completely online and includes a very quick and fair peer-review system. Visit http://www.dovepress.com/ testimonials.php to read real quotes from published authors. 